
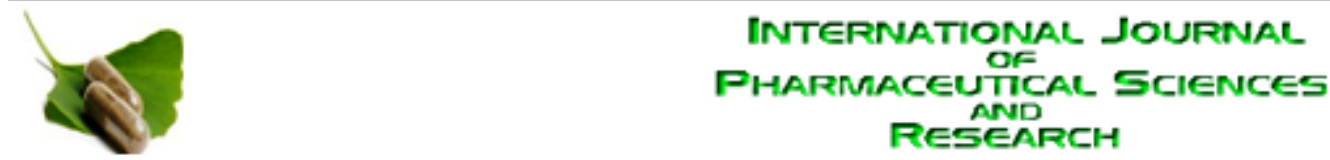

Received on 22 May, 2012; received in revised form 17 July, 2012; accepted 23 September, 2012

\title{
DRUG USE EVALUATION OF BRONCHODIALATORS IN PAEDIATRICS IN A TERTIARY CARE HOSPITAL
}

K.M. Binu, Nimmy N. John, Alan Lee Mathew, H. Doddayya and Ashok Kumar Malpani

Department of Pharmacy Practice, N.E.T. Pharmacy College, Raichur, Karnataka, India

\section{ABSTRACT}

Keywords:

Bronchodilators,

Salbutamol,

Asthma,

Multispecialty

Correspondence to Author:

Nimmy N. John

Department of Pharmacy Practice, N.E.T. Pharmacy College, Raichur, Karnataka,

India

E-mail: nimmydale@gmail.com

\begin{tabular}{|c|c|}
\hline \multirow{2}{*}{ 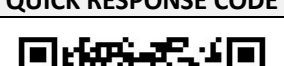 } & \\
\hline & $\begin{array}{l}\text { IJPSR: } \\
\text { ICV- } 4.57\end{array}$ \\
\hline 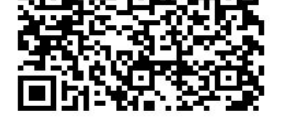 & $\begin{array}{c}\text { Website: } \\
\text { www.ijpsr.com }\end{array}$ \\
\hline
\end{tabular}

The use of bronchodilators has been increasing for the past few decades. The literatures have reported a high rate of adverse events. It has also been found out that beta-agonists are associated with an increased morbidity and mortality rate. Respiratory tolerance develops due to regular use of betaagonists, which are widely prescribed in asthma and bronchiolitis also is of major concern.

Objective: To evaluate the rational use of bronchodilator drugs by analyzing the appropriateness of the prescription.

Methodology: Prospective observational study.

Study site: A 500-bedded Multispecialty Tertiary care Teaching Hospital. Result: In the study population of 133 patients male children were found to be more (58.6\%) than the female children $(41.4 \%)$ Most of the bronchodilators were prescribed for infants (48.1\%). Of the 133 pediatric patients, the major prescription was for SABA (99.2\%). Of which the major prescription was for salbutamol (63.2\%). Most of the Children with asthma were prescribed with combination therapy of salbutamol and ipratropium (81.3\%). In WALRI, patients were prescribed with salbutamol (40.4\%) and in acute bronchiolitis, the major prescription was found to be salbutamol and ipratropium combination (70.3\%). In $52.6 \%$ of the prescriptions bronchodilator were given by nebulization and oral route. $31.6 \%$ were given by nebulization. $95.5 \%$ of patient was prescribed with antibiotics along with bronchodilators, followed by mucolytics $55.6 \%$. Asthma action plan and patient education were not provided by healthcare providers.
INTRODUCTION: Drug use evaluation (DUE) is an ongoing, systematic process designed to maintain the appropriate and effective use of drugs. It involves a comprehensive review of patient's prescription and medication data before, during, and after dispensing in order to assure appropriate therapeutic decision making and positive patient outcomes. Pharmacists participating in DUE programs can directly improve the quality of care for patients, individually and as populations, by preventing the use of unnecessary or inappropriate drug therapy and by preventing adverse drug reactions. Additionally, participation in DUE activities is one means by which pharmacists provide value to the health care system by exerting a positive influence on physician prescribing patterns.

DUE in Paediatrics is important since monitoring the safety of medicine use in children is of paramount importance since, during the clinical development of medicines, only limited data on this aspect are generated through clinical trials. 
World Health Organization has estimated that 15 million disability-adjusted life-years are lost and 250,000 asthma deaths are reported annually worldwide. Among them $34.6 \%$ individuals were of age 18 years or younger.

Although bronchodialators have an undisputed role in the short term management of asthma,their unsupervised use presents potential risks. Cardiac arrhythmias after Salbutamol ingestion is well documented in adults, have not been commonly described in pediatric patients.

Sudden death and atrial arrhythmia induced during salbutamol inhalation through a spacer, extrasystoles after nebulised salbutamol, and unifocal ventricular ectopics, and several ECG changes have been reported during salbutamol infusion in adults. In conclusion children receiving nebulised salbutamol may be at risk of developing cardiac complications, and cardiac monitoring should be considered in these cases. Respiratory tolerance develops due to regular use of beta agonists, which are widely prescribed in asthma and bronchiolitis also is of major concern.

Thus, it is essential to conduct an evaluation on the safe use of bronchodilators.

MATERIALS AND METHODS: The protocol was accepted by Institutional Ethics Committee. It is a prospective observational study conducted at a tertiary care from May 2008 to December 2008. Patients in the pediatric ward prescribed with Bronchodilator were included in the study where as Patients who were prescribed with bronchodilators for surgical prophylaxis were excluded from the study.

All the patients who were prescribed with bronchodilators in the Pediatric ward were included in the study. Only inpatients were included in the study. The demographic data and the bronchodilator prescribed were recorded in the data entry format. A questionnaire was also prepared to understand the parents or caregivers perception about asthma medications.
RESULT: In the study, population of 133 patients male children were found to be more (58.6\%) than the female children (41.4\%). Most of the pediatric patients treated with bronchodilators were infants (48.1\%) followed by children $47.4 \% \%$ and adolescents $3.8 \%$.

Parental social history revealed that $50.4 \%$ were found to be occasional smokers. $48.9 \%$ of the parents have either high school graduate or diploma (Table 1).

\section{LEGEND FOR TABLE 1}

\begin{tabular}{|c|c|c|c|}
\hline $\begin{array}{c}\text { Serial } \\
\text { No. }\end{array}$ & $\begin{array}{c}\text { Parental social history } \\
\text { smoker }\end{array}$ & $\begin{array}{c}\text { No. of } \\
\text { patients }\end{array}$ & Percentage \\
\hline 1 & Daily smoker & 18 & 13.5 \\
\hline 2 & Occasional smoker & 67 & 50.4 \\
\hline 3 & Had never smoker & 40 & 30 \\
\hline 4 & Had quit & 8 & 6 \\
\hline \multicolumn{4}{|c|}{ Parent education } \\
\hline 1 & $<$ High school & 29 & 21.8 \\
\hline 2 & $\begin{array}{l}\text { High school graduate or } \\
\text { general Education diploma }\end{array}$ & 65 & 48.9 \\
\hline 3 & $\begin{array}{c}\text { Some college or technical } \\
\text { training }\end{array}$ & 36 & 27 \\
\hline 4 & Not available & 3 & 2.2 \\
\hline
\end{tabular}

Reason for Admission: The major complaints reported include cough \& breathing difficulty (89.5\%) fever for $74.4 \%$ patients, cold in $60.9 \%$ children, breathing difficulty in $52.6 \%$ patients, wheezing in $12 \%$ children and chest tightness in $8.3 \%$ patients.

Lab investigation: Of the 133 children, the major laboratory investigation performed was determination of differential leukocyte count \& $\mathrm{Hb}$ (96.9\%), TLC (93.9\%), CRP (54.9\%), ESR (25.6\%), and IgE (19.5\%). Pulmonary function tests were performed only for $4.5 \%$ of the study population. Chest X-ray was performed for $72.9 \%$ patients and absolute eosinophil count was performed in $20.3 \%$ of the study population.

Various clinical conditions under Therapy: Wheezing associated with lower respiratory tract infection was the most predominant disorder found in $35.3 \%$ children followed by acute bronchiolitis in 20.3\% patients, acute asthma in $12 \%$ patients (table 2 ). 


\section{LEGEND FOR TABLE 2}

\begin{tabular}{cccc}
\hline S. No. & Disorders & No. of patients & Percentage (\%) \\
\hline 1 & Wheezing associated with lower respiratory tract infections & 47 & 35.3 \\
2 & Acute bronchiolitis & 27 & 20.3 \\
3 & Acute bronchitis & 9 & 5.2 \\
4 & Upper respiratory tract infections & 4 & 3 \\
5 & Short pyrexia & 11 & 8.2 \\
6 & Acute asthma, Hyper reactive airway disease & 16 & 12 \\
7 & Pneumonia & 6 & 4.5 \\
8 & Acute otitis media & 6 & 4.5 \\
9 & Pyrexia of unknown origin & 7 & 5.2 \\
\hline
\end{tabular}

The majority of the clinical conditions were in moderate state which was about $39.8 \%, 33.1 \%$ of cases were in severe condition and $27.1 . \%$ were in mild condition.

Category of Bronchodialator Prescribed: Of the 133 pediatric patients the major prescription was for SABA(99.2\%). $50.3 \%$ of the patients were prescribed with anticholinergics, methyl xanthines were prescribed for $7.5 \%$ patients only.

Of the 133 pediatric patients the major prescription was for salbutamol (63.2\%). 50.3\% of the patients were prescribed with Ipratropium + salbutamol combination and $30 \%$ with terbutaline alone. Levosalbutamol was prescribed for $18.8 \%$ patients. $4.5 \%$ patients were prescribed with salbutamol + choline theophylline combination. Only $2.3 \%$ of patients were prescribed with doxophylline \& ipratropium each.

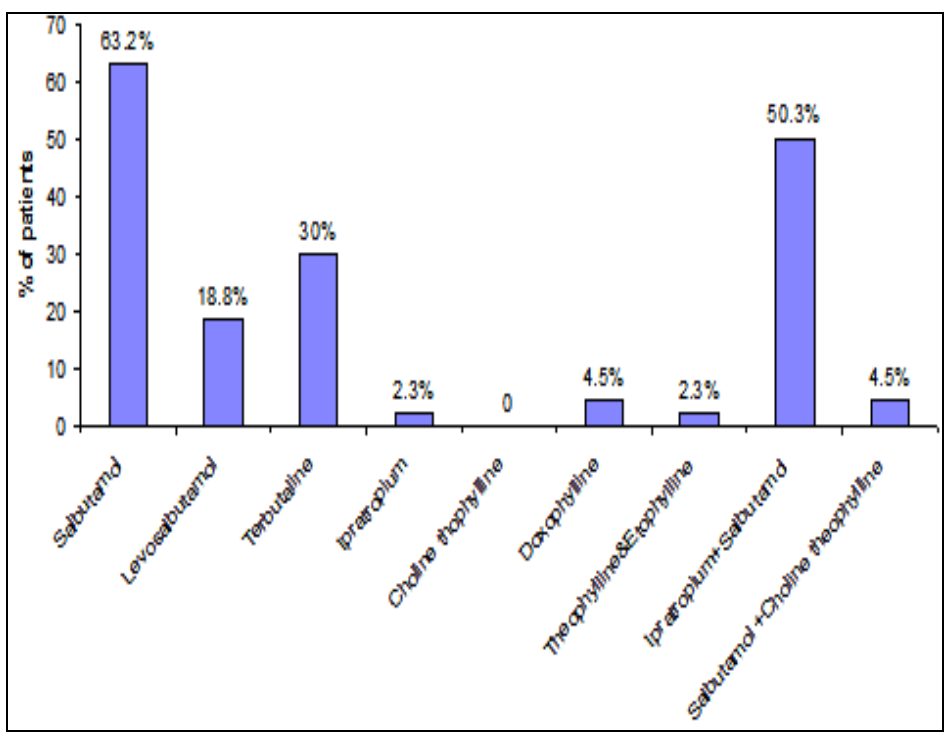

LEGEND FOR FIGURE 1
In WALRI the major prescription was for salbutamol alone $(40.4 \%)$ and $36.2 \%$ were prescribed with terbutaline. $31.9 \%$ of the patients were prescribed with salbutamol + ipratropium combination. Levo salbutamol was prescribed for $21.3 \%$ of patients. Only $6.3 \%$ of pediatric patients were prescribed with ipratropium alone.

In acute bronchiolitis, the major prescription was found to be for salbutamol + ipratropium combination (70.3\%) followed by $51.9 \%$ for salbutamol. Terbutaline was prescribed for $18.5 \%$ and only $7.4 \%$ patients were prescribed with lev-osalbutamol.

Route of Administration: In $52.6 \%$ of the prescriptions bronchodilator therapy was given by nebulization and oral route. $31.6 \%$ were given by nebulization and $9 \%$ were given by oral, only $2.2 \%$ accounted for inhalation and $1.5 \%$ were given by IV + Neb, Neb +Inh, Neb + Oral + Inh each.

Major prescriptions of bronchodilator drugs were with antibiotics $95.5 \%$ followed by mucolytics $55.6 \%$. Other concurrent prescriptions were with steroids $38.3 \%$, expectorants $48.9 \%$, electrolytes $54.1 \%$, analgesics \& antipyretics $18.4 \%$, vitamins $8.3 \%$, antivirals and anti histamines $5.3 \%$ each and anti ulcer $6.0 \%$.

It was found that $77.4 \%$ of pediatric patients not received any oxygen supplementation. Only intravenous feeding was given to $58.6 \%$ of study population.12.8\% received both IV \& Oxygen and $9.7 \%$ were given oxygen only.

Awareness of Preceptors: $75 \%$ of the care givers were found not familiar to bronchodilators and $25 \%$ were familiar. 
Formulation preference by Patients: From the study population of 16 parents whose children were under bronchodilator therapy were asked to inform about their preferences of the treatment, $100 \%$ reported that they preferred to use syrups, $87.5 \%$ preferred to use nebulizer,50 \% preferred to use MDI with spacer, $75 \%$ preferred to use tablets. and $12.5 \%$ preferred to use DPI.

DISCUSSION: There were, in total, 133 prescriptions for bronchodilator drugs recorded in pediatric ward. Major class of bronchodilator prescribed was short- acting $\beta_{2}$ agonists in $99.2 \%$ of patients followed by anticholinergics $50.3 \%$ where guidelines recommend that short- acting $\beta_{2}$ agonists should be used in acute conditions. LABA have no role in the management of acute asthma, so they were not prescribed.

Salbutamol (63.2\%) alone was the major prescription for most of the patients.Studies says that children receiving nebulised salbutamol may be at risk of developing cardiac complications, and cardiac monitoring should be considered in these cases. $50.3 \%$ of the patients were prescribed with Ipratropium and salbutamol combination. This combination were most commonly used in asthma (81.3\%), WALRI(40.4\%), and bronchiolitis (70.3\%). Inhaled ipratropium may add to the bronchodilator benefits seen with inhaled shortacting $\beta_{2}$ agonists. The addition of ipratropium bromide to beta ${ }_{2}$ agonist may be more effective than beta ${ }_{2}$ agonist alone at reducing the need for further drug treatment at 45 minutes in infants presenting to emergency departments, but not at improving "excellent" clinical response

In $52.6 \%$ of the prescriptions bronchodilator therapy was given by nebulization and oral route. $31.6 \%$ were given by nebulization. Guidelines also says that nebulizer may be suitable for all age groups and recommended mode for patients with severe episodes or on ventilator. A study by Jougon (2003) ${ }^{47}$ reported that nebulization of bronchodilators develop spontaneous pneumomediastinum and subcutaneous emphysema.

Major prescriptions of bronchodilator drugs were with antibiotics $95.5 \%$ followed by mucolytics $55.6 \%$. Other concurrent prescriptions were with steroids $38.3 \%$, expectorants $48.9 \%$, but guidelines recommended that antibiotics are not routinely required since bacterial infections seldom trigger asthma . Consider antibiotics only in those who do not improve in response to bronchodilators, have purulent secretions or have radiological hematological evidence of infection ${ }^{5}$.

In a review of use of Fixed Combination Preparations of Inhaled Short Acting Beta-2 Agonists and Inhaled Corticosteroids, by Gupta (2000) ${ }^{41}$. Regular use of short-acting beta- 2 agonists or their combinations with inhaled steroids in asthma patients becomes a matter of serious concern. Such a use could be potentially harmful to the patient as it may be associated with increased morbidity and mortality due to asthma because of poor asthma control and because of the delay in seeking medical advice during acute episodes.

It was found that bronchodilators were routinely prescribed for children with bronchiolitis. Salbutamol was prescribed for $51.9 \%$ and salbutamol + ipratropium combination were given to $70.9 \%$ of patients.

Similar study conducted by Franz ${ }^{48(2008)}$ reported that no medications were used for mild or moderate bronchiolitis. Inhaled [beta]-agonists were used for moderate and for severe bronchiolitis and another study conducted by Karadag $2008{ }^{13}$ reported that Clinical scores and oxygen saturation levels improved more rapidly in the bronchodilator groups than in the placebo group up to $24 \mathrm{~h}$, but these drugs did not have a sufficient effect to change the natural course of the disease. New Bronchiolitis Guidelines 2006 American Academy of Pediatrics Subcommittee on Diagnosis and Management of Bronchiolitis recommended that Bronchodilators should not be used routinely for management. An optional trial of an - or ß-agonist should be continued only if objective evaluation indicates a clinical response. Most positive studies of bronchodilators for management of bronchiolitis show transient improvement of unclear clinical significance 49 .

It was found that $77.4 \%$ of pediatric patients not received any oxygen supplementation where as guidelines recommended that oxygen must always be administered along with nebulized SA $\beta_{2}$ agonists. Oxygen saturation must be maintained $>91 \%$.Oxygen and intravenous feeding must maintained. 
The child may need more than maintenance fluids initially due to increased insensible losses. Fluids are also required to make secretions less viscous ${ }^{50}$.

As the children were prescribed with very few drugs, the chances of drug interactions were rare. The major drug interaction of bronchodilators were observed with steroids.

CONCLUSION: The study found over use of antibiotics, sedatives and mucolytics and under use of steroids. Bronchodilator use was optimal but evaluation of therapy was not done commonly. Asthma therapy does not reflect guideline recommendations. Asthma action plan and patient education were not provided by healthcare providers. The study highlighted the need for a local protocol and continuing staff and parent education.

\section{REFERENCE:}

1. The Academy of Managed Care Pharmacy. Concepts in Managed Care Pharmacy: Drug use evaluation. Revised: November 9, 1999. Available from URL: http://depts.washington.edu/ expharmd/ExPharmD.DUE. html

2. World Health Organization 2007. Promoting safety of medicine for children available a from URL http://www.who.int/medicines /publications/ essentialmedicines/Promotion_safe_med_childrens.pdf

3. Undem B J. Pharmacotherapy of asthma. In: Brunten LL, Lazo JS,Parker KL,editors.Goodman \& Gilman's The pharmacological basis of therapeutics. $11^{\text {th }}$ ed. USA: Mc Graw-Hill Companies; 2006. 717-730

4. Cada DJ, Covington TR, Generali JA, Hussar DA, Lasagna L, Selevon JR. editors. Drug facts and comparisons. 57 th edition, USA: Facts and Comparisons 2003. 721-767.

5. Indian academy of pediatric medicine:asthma by consensus( consensus statement on the diagnosis and management of asthma in children. [online]. 2003 available from URL http//grand am.websie wlcome.com/IAP files/asthma-3 pdf.

6. Kelly HW, Sorkness CA. Asthma. In Dipiro JT, Talbert RL,Yees GC, Matzke GR, Wells BG,Posey LM,editors. Pharmacotherapy: A pathophysiological approach. $6^{\text {th }}$ ed .New York:Mc Graw-Hill; 2005. 503.

7. Sharma GD, Gupta P. Asthma [online] 2009. Available from URL http://emedicine.medscape.com/specialties.html
8. Kemp JP,Kemp JA .Management of asthma in children 2001; Vol. 63/No.http://www.aafp.org/afp/20010401/1341.html

9. Guidelines for the diagnosis and management of asthma, Expert Panel Report 2,NIH, Published on Aug 2007.Available from URL http:// www.nhlb.nih.gov/about/naepp.pdf

10. Daniel L.L, Abhinav G, Leila J.H, Scott S, Dean J.J, James L.C. A prospective randomized controlled blinded study of three bronchodilators in infants with respiratory syncytial virus bronchiolitis on mechanical ventilation. Journal of Pediatric Critical Care Medicine 2008; 9(6): 598-604.

11. Beydon N, Buila M .C, Peiffer C, Bernard A, Zaccaria I, Denjean A. Can bronchodilator response predict bronchial response to methacholine in preschool coughers? Journal of Pediatr Pulmonol 2008 Aug;43(8):815-21.

12. Chang $A B$, Halstead RAP, Petsky HL Methylxanthines for prolonged non-specific cough in children 2008; Available from URL http://www.cochrane.org/index.html

13. Karadag B, Ceran O, Guven G, Dursun E, Ipek I O, Karakoc F, et al. Efficacy of Salbutamol and Ipratropium Bromide in the Management of Acute Bronchiolitis - A Clinical Trial Respiration 2008; 76 (3) :283-287.

14. Sharma A.S, , Litonjua A A A, Tantisira KGA, Fuhlbrigge A LA , Szefler S J A, Strunk R C A et al. Clinical predictors and outcomes of consistent bronchodilator response in the childhood asthma management program . Journal of allergy and clinical immunology 2008 Nov; 122(5) : 921-928.

15. Rodriguez-Martinez CE, Sossa M, Lozano JM Commercial versus home-made spacers in delivering bronchodilator therapy for acute therapy in children. Available from URL http://www.cochrane.org/ reviews /index. Html.

16. Song $T W, \operatorname{Kim} K W, \operatorname{Kim} E S$, Park J W, Sohn H M, Kim K. Utility of impulse oscillometry in young children Utility of impulse. Division of Allergy and Respiratory Medicine Jan 2008 Available from URL: http://www3.interscience.wiley.com.html.

17. Bagai S, Dhir R: Oral xanthines in the management of childhood asthma: Time for reappraisal. Pediatrics Today 2008 Sep;11(5):231-234

18. Sing V. What is new in the management of childhood asthma? Indian Journal of Pediatrics 2008; 75(8):845-853

19. Singhania N, Dhamija R, Lodha R, Kabra S K. Salmeterol vs. formoterol: a comparison of rapid bronchodilator effect in a randomized controlled trial. Journal of Indian Pediatrics 2008; 45:225-228 Available from URL http://indianpediatrics.net/index.html

20. James J M. Value of the Bronchodilator Response in Assessing Controller Naïve Asthmatic Children. Pediatrics O ct 2008 URL http://pediatrics.aappublications.org.html

21. Bagai S. Doxofylline in pediatric asthma. Pediatrics Today 2007 Nov-Dec; 10(6):310-313.

How to cite this article:

Binu KM, John NN, Mathew AL, Doddayya H and Malpani AK: Drug Use Evaluation of Bronchodialators in Paediatrics in a Tertiary Care Hospital. Int J Pharm Sci Res. 3(10); 3983-3987. 